\title{
Empirical Study on the Entrance Examination of Students in Applied General Agricultural Colleges- Taking the X School of Heilongjiang Bayi Agricultural University as an Example
} QU Yanpeng, YANG Yanqiu, ZHANG Aizhong, TONG Dandan, SHAN Xufei, LV Tian, LIAN Shuai"

College of Animal Science and Veterinary Medicine, Heilongjiang Bayi Agricultural University, Daqing, 163319, P. R. China

DOI: $\underline{10.36347 / \text { sjebm.2020.v07i03.002 }}$

| Received: 04.03.2020 | Accepted: 13.03.2020 | Published: 18.03.2020

*Corresponding author: Shuai Lian

Abstract

Review Article

Rural rejuvenation is more and more urgent for the new talents of agriculture, so the applied general agricultural colleges should train the complex applied and technical talents to improve the students' ability of employment and entrepreneurship. Rational analysis of the application of ordinary agricultural colleges and universities students' postgraduate examination, for the establishment of applied colleges and universities talent training goals and programs to provide reference basis is particularly important. Based on the analysis of the data of Heilongjiang Bayi Agricultural University's X school, from 2016 to 2019, the number of applicants for 985 and 211 key institutions is increasing, but the success rate is decreasing. According to the data for 2019, the number of academic graduate students is much higher than the number of professional graduate students; the number of students admitted to our university is relatively large; and the foreign language plays a decisive role in the four subjects of postgraduate examination. Put forward to strengthen the ideological consciousness of serving "agriculture, countryside and farmers ", strengthen the guidance and service of postgraduate examination, do a good job of students' career planning, improve students comprehensive quality, and make positive contributions to rural revitalization.

Keywords: Postgraduate examination; applied type; agricultural colleges; students.

Copyright @ 2020: This is an open-access article distributed under the terms of the Creative Commons Attribution license which permits unrestricted use, distribution, and reproduction in any medium for non-commercial use (NonCommercial, or CC-BY-NC) provided the original author and source are credited.

\section{INTRODUCTION}

General agricultural colleges and universities have trained a large number of professionals for the agricultural and animal husbandry industry in China. With the rapid development of the Chinese economy, the employment of undergraduate graduates of ordinary agricultural colleges and universities has gradually diversified, and the admission to master's degree has gradually become one of the important choices for undergraduate graduates of ordinary agricultural colleges and universities. In 2015, the Ministry of Education, the State Development and Reform Commission and the Ministry of Finance jointly issued the "Guidance on guiding the transformation of some local undergraduate colleges and universities to the applied type" to promote the transformation and development of some colleges and universities. Heilongjiang Bayi Agricultural University, which is located in northern China, is a full-time general agricultural college in the province and is listed as the characteristic applied undergraduate demonstration construction university in Heilongjiang Province. Taking the X School of August 1, Heilongjiang Bayi
Agricultural University as an example, the author carries on the data arrangement and the induction to the 2016-2019 undergraduate graduate entrance examination, summarizes the existing problems, puts forward the pertinence suggestion, in order to understand the applied general agricultural college undergraduate graduate entrance examination situation, provides the reference for the employment guidance work.

The Change of the Number of Entrance Examination and Admissions in the Nearly Ten Years in China

In recent years, while expanding the enrollment scale of undergraduate colleges and universities, the employment of undergraduate graduates of ordinary agricultural colleges presents some difficulties. With the continuous development of China's economy, the demand and social status of highly educated talents are on the rise, and the number of applying for graduate students is increasing year by year. 


\begin{tabular}{l} 
Sheet-1: Statistics on the Number of Entrance Examination and Admission in China from 2010 to 2019 \\
\hline
\end{tabular}

According to the Ministry of Education's official data sheet $1^{[1]}$, from 2010 to 2019 , the number of postgraduate entrance examination increased from 1.406 million to 2.9 million, and the registration growth rate showed an upward trend, but the number of admission to graduate school increased from 474,000 to 720,000 , with the examination record ratio increasing year by year. The number of Chinese graduate students applying for an entrance examination for a master's degree in 2020 reached 3.41 million, an increase of more than 500,000 over 2019, an increase of more than 17 percent, another record high.
Empirical Studies on the Entrance Examination of Students in Applied General Agricultural Colleges

\section{Registration and admission of students}

As can be seen from Sheet 2, the total number of graduates in 2016-2019 is increasing year by year. The increase has also increased from 284 in 2016 to 396. The number of students applying for graduate students is also increasing year by year, from 145 in 2016 to 220 in 2019 , and the registration rate is on the rise. The number of admission to the postgraduate examination has not changed much, and the success rate of the postgraduate examination shows a downward trend. The success rate of the postgraduate examination is declining year by year, with $44.72 \%$ in 2016 down to $30.56 \%$ in 2019.

Sheet-2: Students applying for postgraduate studies and admission in 2016-2019

\begin{tabular}{|l|l|l|l|l|}
\hline Program & 2016 & 2017 & 2018 & 2019 \\
\hline Total number of graduates & 284 & 316 & 370 & 396 \\
\hline Number of applicants & 145 & 146 & 219 & 220 \\
\hline Registration rate & $51.06 \%$ & $46.20 \%$ & $59.19 \%$ & $55.56 \%$ \\
\hline Admission to the postgraduate examination & 127 & 141 & 129 & 121 \\
\hline Success rate of postgraduate examination & $87.59 \%$ & $96.58 \%$ & $58.90 \%$ & $55.00 \%$ \\
\hline Entrance examination rate & $44.72 \%$ & $44.62 \%$ & $34.86 \%$ & $30.56 \%$ \\
\hline
\end{tabular}

\section{Enrolment and Admission of Students}

As can be seen from Table 3, from 2016 to 2019 , the number of applicants for graduate students in our school has changed little, the number of applicants for 985 and 211 key colleges is increasing, the proportion of students applying for this school is decreasing, and the proportion of applicants for 985 and 211 key colleges is increasing. In 2019, the number of applicants for 985 and 211 key colleges and universities and the proportion of applicants for 985 and 211 key colleges and universities are far higher than the number of applicants for postgraduate studies and the proportion of applicants for this university. The proportion of students admitted to our school has changed little, and the proportion of students admitted to 985 and 211 key colleges and universities is decreasing year by year. The success rate of students taking admission to our school is decreasing, and the success rate of admission to 985 and 211 key colleges and universities is decreasing, and the decrease is large, from $78.26 \%$ in 2016 to $30.23 \%$ in 2019 . The success rate of this school is much higher than that of 985 and 211 key colleges. 
Sheet-3: Enrolment of Students in Universities from 2016 to 2019

\begin{tabular}{|l|l|l|l|l|}
\hline Program & $\mathbf{2 0 1 6}$ & $\mathbf{2 0 1 7}$ & $\mathbf{2 0 1 8}$ & $\mathbf{2 0 1 9}$ \\
\hline Number of applicants & 145 & 146 & 219 & 220 \\
\hline Number of applicants to the original university & 65 & 70 & 69 & 72 \\
\hline Proportion of entries & $44.83 \%$ & $47.95 \%$ & $31.51 \%$ & $32.73 \%$ \\
\hline Proportion of entries to the original university & 54 & 61 & 52 & 54 \\
\hline Proportion of admission & $42.52 \%$ & $43.26 \%$ & $40.31 \%$ & $44.63 \%$ \\
\hline Success proportion of admission to the original university & $83.08 \%$ & $87.14 \%$ & $75.36 \%$ & $75.00 \%$ \\
\hline Enrolment in 985,211 institutions & 69 & 66 & 130 & 111 \\
\hline proportion of entries & $47.59 \%$ & $45.21 \%$ & $59.30 \%$ & $50.45 \%$ \\
\hline Admission to 985/211 & 54 & 56 & 49 & 39 \\
\hline Proportion of examinations & $42.52 \%$ & $39.72 \%$ & $37.98 \%$ & $32.23 \%$ \\
\hline Success proportion of admission to 985/211 & $78.26 \%$ & $84.85 \%$ & $37.69 \%$ & $35.14 \%$ \\
\hline
\end{tabular}

\section{Type of graduate student admission in 2019}

The author has counted the type of students admitted to graduate students in 2019, as shown in figure 1,40 of the 121 students were admitted to professional master's degree, accounting for $33.05 \%$, and the number of students admitted to academic graduate students was 81 , accounting for $66.94 \%$. The number of admitted academic graduate students is much higher than that of professional graduate students.

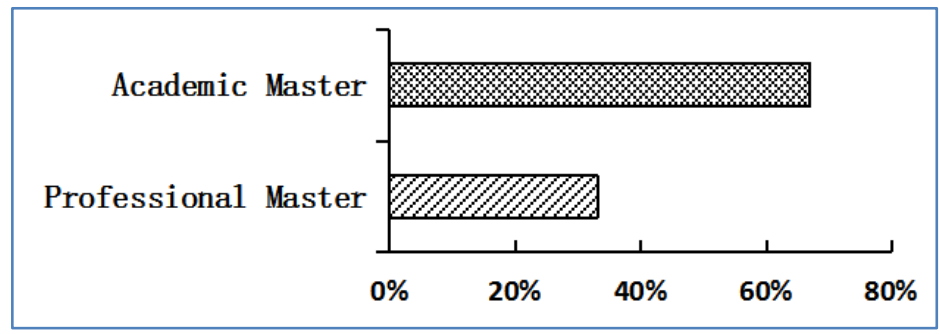

Pic-1: Type of application

\section{Student Admissions to Graduate Schools in 2019}

In 2019, the author counted the students' admission to graduate school in 2019, as shown in figure 2, the students admitted to graduate school were distributed in 26 schools, of which the proportion of the school was $46.28 \%$, which was relatively large. Northeast Agricultural University, Guangxi University and Jilin University accounted for 12.70 percent,4.96 percent and 4.13 percent respectively, ranking two, three and four respectively. It can be seen that the number of admission to our school and 985,211 key colleges and universities is the majority. The same is true for key schools, where students choose to be relatively close geographically.

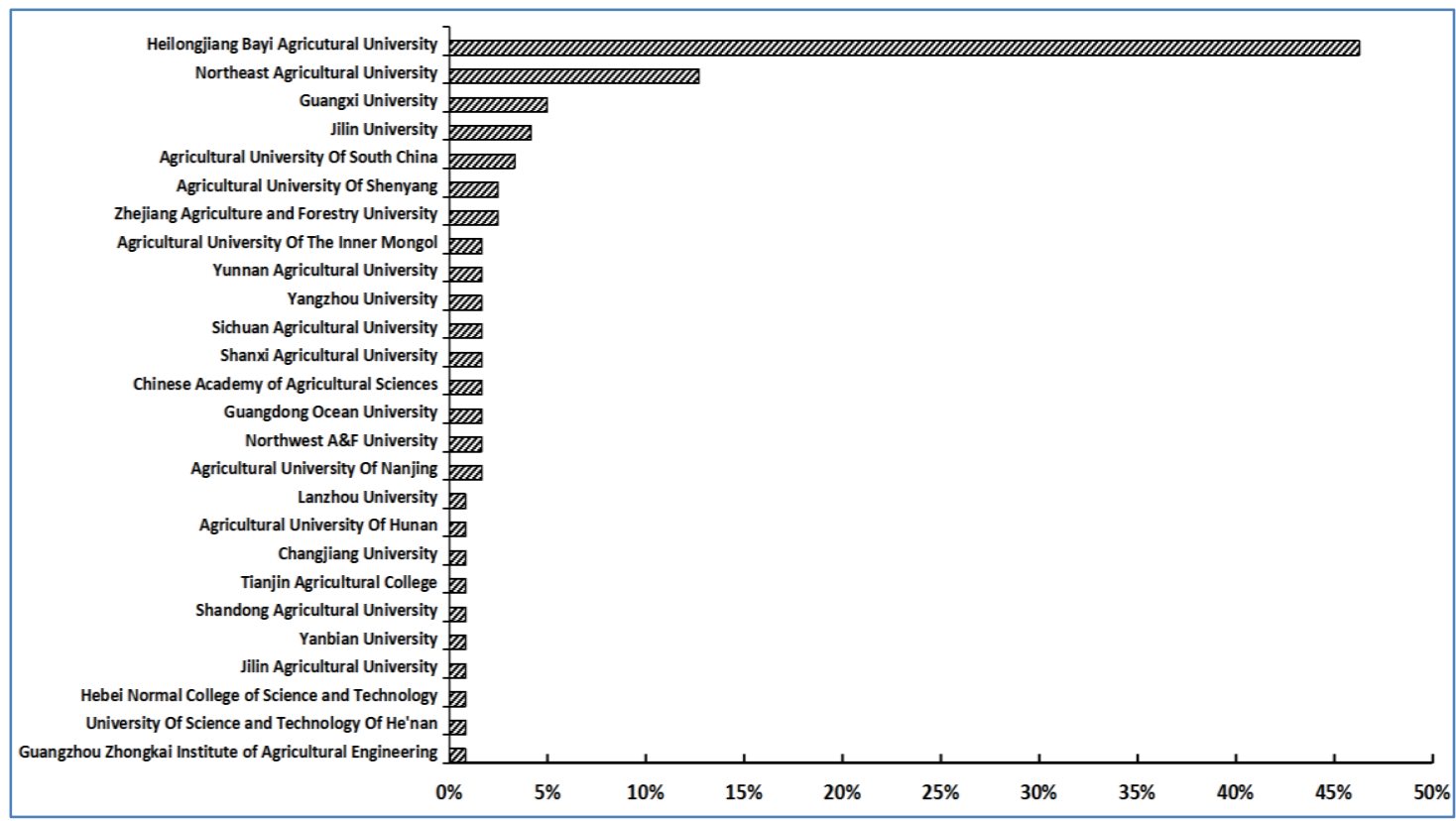

Pic-2: Students admitted to graduate school in 2019 


\section{Failure of postgraduate students in $\mathbf{2 0 1 9}$}

As shown in figure 3, the number of people who have not crossed the line in politics accounted for $14.14 \%$, the number of people who have not crossed the line in foreign languages accounted for $61.62 \%$, the number of people who have not crossed the line in one business course accounted for $21.21 \%$, the number of people who have not crossed the line in two business courses accounted for $33.33 \%$, the total number of people who have not crossed the line in politics accounted for $1.67 \%$, the total number of people who have not crossed the line in foreign languages accounted for $39.39 \%$, and the total number of people who have not crossed the line in foreign languages or politics accounted for $17.17 \%$. The loss of foreign language resulted in the loss of postgraduate examination is relatively large, the failure of political achievement leads to the relatively small loss of postgraduate examination, and the loss of business class two is higher than that of business class one. The total score of foreign language and political achievement is relatively small, the total score of foreign language is relatively high, and the foreign language plays a decisive role in the four subjects of postgraduate examination.

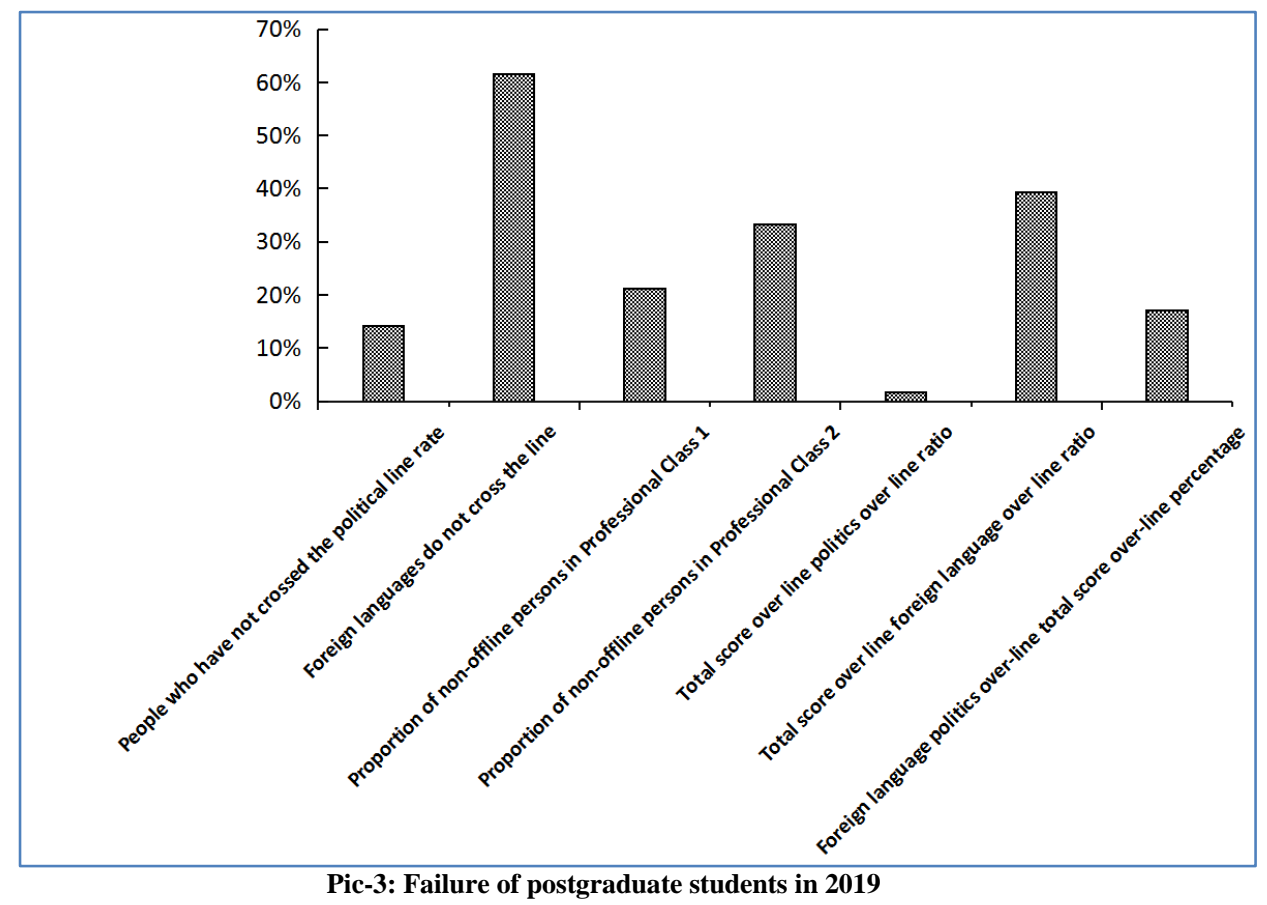

\section{ANAL YTICAL DISCUSSION}

Focusing on the goal of cultivating talents in applied agricultural colleges and universities, the ideological consciousness of serving "agriculture, countryside and Farmers" should be strengthened

The 19th National Congress of the Communist Party of China proposed that the implementation of the strategy of rural revitalization should foster a "three rural" work force that understands agriculture, loves the countryside and loves the peasants. Applied general agricultural colleges and universities have the responsibility to consolidate the ideological basis of young college students to know agriculture and love agriculture, to strengthen agricultural basic theory education and practical ability training, and to guide agricultural college students to take postgraduate studies as a way to enhance their ability to promote service "agriculture, countryside and farmers ", rather than the purpose. In order to improve students' ability of employment and entrepreneurship, applied colleges and universities should closely focus on the goal of personnel training and the actual situation of school personnel training, at the same time, strengthen the investigation of students' actual situation, put forward the ideas of students' education and management in accordance with the national conditions and school conditions, make effective use of college students' career planning education, and guide students to position their personal development direction reasonably ${ }^{[2]}$.

Give full play to the role of the main channel of ideological guidance in colleges and universities, and strengthen the guidance and service of postgraduate examination

It can be seen from the change of the number of applicants and the number of applicants in recent ten years that the number of students in Chinese colleges and universities is increasing year by year, and from the survey of four consecutive years, it can be seen that the number of graduates of applied agricultural colleges and universities is also increasing year by year. College students are keen to take the postgraduate examination, which not only shows that the society attaches importance to and respects the knowledge and highlevel talents, but also shows that the development level 
of the national economic and cultural construction has reached a new stage [3]. However, we must also see that the motivation of the students also reflects the negative factors of the fever of postgraduate examination and the problems that are contrary to the principles of applied higher education. We must give full play to the main channel of the school to guide the students, increase the guidance to the students' motivation of postgraduate examination, reduce the phenomenon of high-level examination-oriented education, educate the students to correct the motivation of postgraduate examination, correctly understand and treat the postgraduate examination, so that the higher education can adapt to the quality education in the aspects of postgraduate examination, learning management mode and the concept of talent, and so as to adapt to the goal of postgraduate training education.

To guide college students to do a good job of career planning, to help students establish a correct concept of postgraduate examination choice

With the continuous development of China's economy and the continuous improvement of residents' living standards, the economic pressure of students is reduced, influenced by the employment environment and social concept, the willingness to take the postgraduate examination is constantly increasing, and the proportion of students taking the postgraduate examination is constantly increasing. However, according to the data of the survey, the students still pay attention to the school level in the selection of the entrance examination, the phenomenon of piling up the examination is more obvious, and the success rate of the entrance examination is on the low side. It is necessary to meet the needs of individual development and provide timely and effective education and guidance for students in applied agricultural colleges and universities [4]. The purpose of career planning education is to guide students to plan their personal development goals reasonably, and the purpose of postgraduate entrance examination is to relieve the pressure of employment and further enhance their comprehensive ability. It is necessary to strengthen the analysis of students' personal ability and characteristics, so that students can make rational choices from their own actual and internal needs, and not blindly take the postgraduate examination as a tool for employment, and deviate from the goal of talent training in applied ordinary agricultural colleges and universities. On the basis of fully and thoroughly understanding their own characteristics and advantages, we should understand the overall needs of the society and the state for talents and make personal development plans suitable for ourselves.
Strengthen the construction of style of study, consolidate the professional foundation of college students, and improve the comprehensive quality.

It can be seen from the failure of the students that foreign languages play a decisive role in the four subjects. The construction of style of study is an important link in the cultivation of talents in colleges and universities, and it is a necessary way to improve the comprehensive quality of individuals, whether students go to school or employment, strengthen the construction of style of study, consolidate the professional foundation, and cultivate good comprehensive quality and ability are necessary. First, it is necessary to strengthen basic professional education. Strengthen the undergraduate stage, including English, professional courses and other basic subjects, and further consolidate the professional foundation of college students. It also needs the effective integration of professional practical ability and professional basic knowledge. Second, it is necessary to attach importance to students' professional scientific research and practical training, and professional practice and scientific research training is also important parts to enhance the competitiveness of postgraduate students.

\section{ACKNOWLEDGMENTS}

This work was supported by Heilongjiang province education science 13th five-year plan youth special project (NO. NDJY1905 and NO.GJD1319017).

\section{REFERENCE}

1. Statistics and Analysis on the Number of Entrance Examination and Admissions in China (19942020)[OL] School Information of Wendu,2019-1228.https://baijiahao. baidu.com/ s? i $\mathrm{d}=1654070134947932452$.

2. Zeng Rong, Sheng Youxing. A Practical Study of College Student Career Planning and Education Model [J]. Shandong Social Sciences. 2011 (2): 245-246.

3. Cai Hongjian. It is not advisable for college students to take the entrance examination blindlyReflection on the phenomenon of low-grade entrance examination $[\mathrm{J}]$. Peoples'Forum. 2018(36):106-108.

4. Shao Gang, Cui Ying, Dai Yun. Research on postgraduate examination behavior of university students in agricultural colleges-Take Nanjing Agricultural University as an example [J]. Agricultural Education in China. 2019, 20(06):7683. 